\title{
MONITORING OF BOVINE VIRAL DIARRHOEA VIRUS (BVDV) INFECTION IN POLISH DAIRY HERDS USING BULK TANK MILK SAMPLES
}

\author{
ALEKSANDRA KUTA, MIROSŁAW P. POLAK, MAGDALENA LARSKA, \\ AND JAN F. ŻMUDZIŃSKI \\ Department of Virology, \\ National Veterinary Research Institute, 24-100 Pulawy, Poland \\ aleksandra.kuta@piwet.pulawy.pl
}

Received: February 25, 2013

Accepted: May 10, 2013

\begin{abstract}
The aim of the study was to evaluate the status of bovine viral diarrhoea virus (BVDV) infection in selected dairy herds in Poland with the use of commercial enzyme linked immonosorbent assay for the detection of specific antibodies (BVDV-Ab ELISA) and reverse transcription-polymerase chain reaction (RT-PCR) for the detection of viral RNA, using bulk tank milk (BTM) samples. Two hundred and thirty-one samples of BTM were collected from 99 dairy herds in Poland. The herds were divided into four different classes according to the Swedish system of classification. The results showed that $70.7 \%$ of herds were BVDV antibodypositive. High levels of antibodies in $52.85 \%$ (37 herds in class 3 ) of all antibody positive herds indicated acute BVDV infection. Thirty five samples with the highest antibody levels were tested by RT-PCR and five of them were positive for viral RNA. Dairy herds in Poland have high levels of antibodies against BVDV in BTM. Since no vaccination was implemented in the herds tested, high seroprevalence of BVDV antibodies in cattle indicates the widespread of BVDV infection in Polish cattle.
\end{abstract}

Key words: bovine viral diarrhoea virus, bulk tank milk, Ab ELISA, RT-PCR, Poland.

Bovine viral diarrhoea virus (BVDV) is an important pathogen of dairy cattle worldwide (7). BVDV, classical swine fever virus (CSFV), and border disease virus (BDV) belong to the genus Pestivirus within the family Flaviviridae (6). Bovine viral diarrhoea (BVD) is a widespread infection affecting mainly cattle but also other ruminants such as sheep and goats $(2,3)$. Seroprevalence of BVDV in cattle varies between different regions of the world from $12 \%$ to $89 \%$. Studies conducted in 2010 , have shown a high prevalence of BVDV infection in dairy cattle in Poland, especially in large herds (21). Percentage of infected herds ranged from $53.9 \%$ to $100 \%$ and depended on the size of a herd. Most primary infections are subclinical, but BVDV can lead to: reduced milk production, diarrhoea, respiratory disorders, infertility, abortion, or stillbirth (8). During the first 40-120 d of pregnancy, infection of pregnant cows or heifers might lead to the birth of persistently infected (PI) calves (16). Superinfection of PI viremic animals with a cytopathic strain leads to fatal mucosal disease (1).

Control of BVDV is a very complicated and long lasting process. PI animals may be missed if laboratory monitoring is not implemented at herd level. These animals shed significant load of BVDV throughout their entire life and they are the main source of infection (25). Removing PI animals from the herd is the most efficient method of controlling and preventing the disease from spreading (22). This is the reason why cattle should be constantly tested for the presence of BVDV. Farmers' expectation is that this would be done at the lowest possible cost. One of such options is testing the bulk tank milk (BTM) samples. The presence of single PI animals in a herd ( $1 \%-2 \%$ prevalence), is enough to mount significant levels of neutralising antibodies, which can be detected in milk of the herdmates having contact with the virus shedder. This approach was implemented first in Sweden, where dedicated cut off values (based on optical density readouts from ELISA) were allocated to different epizootic classes of milking herds with respect to BVDV infection (17). Similar approach was used to identify possible PI carriers by testing pregnant animals for antibodies in late pregnancy (13). Animals with high levels of neutralising antibodies were at risk of giving birth to PI calves. Testing BTM is also successfully implemented in herds free from BVDV infection in the monitoring programmes directed at the identification of new sources of the virus in a herd based on the detection of seroconversion (20).

The aim of the study was to assess the status of BVDV infection in selected dairy herds based on BTM testing using ELISA and RT-PCR as the cheap testing options, yet providing required level of sensitivity and accuracy. 
Table 1

Number of herds examined and average number of milking cows per herd per province

\begin{tabular}{lcc}
\hline Province & Number of herds & Average size \\
\hline Łódzkie & 1 & 123 \\
\hline Kujawsko-Pomorskie & 1 & 340 \\
\hline Warmińsko-Mazurskie & 1 & 80 \\
\hline Zachodnio-Pomorskie & 2 & 305 \\
\hline Podlaskie & 5 & 94 \\
\hline Wielkopolskie & 6 & 359 \\
\hline Mazowieckie & 9 & 88 \\
\hline Lubelskie & 74 & 37 \\
\hline Total & 99 & 217
\end{tabular}

\section{Material and Methods}

The material for the study consisted of 231 samples of BTM collected once or several times from 99 dairy herds located in eight provinces of Poland (Table 1). If a given herd had a history of BVDV vaccination in the past it was excluded from the analysis.

From forty-five out of 99 herds, two to six BTM samples were collected at different time-points with interval of 3 to 30 months between the first and the last collection. The number of milk samples in each BTM was between 12 and 556 depending on the number of milking cows in a given herd. The SVANOVIR BVDV-Ab ELISA screening test (SVANOVA, Sweden) was used to detect antibodies in all BTM samples. Twenty eight samples were tested by the second SVANOVIR BVDV-Ab ELISA, confirmation format (SVANOVA, Sweden) for comparison and result verification.

Milk was collected in $8 \mathrm{~mL}$ plastic tubes, each containing ProClin 150 as preservative. The skimmed milk for ELISA was collected from below the fat layer after centrifugation of whole milk for $10 \mathrm{~min}$ at $3,000 \mathrm{~g}$ at $4{ }^{\circ} \mathrm{C}$. The results of antibody ELISA were interpreted according to the Swedish system of classification (17). Herds were allocated into four different classes based on the corrected optical density (COD) value obtained in screening ELISA. Class 0 - (COD: <0.04), class 1 (COD: 0.05-0.24), class 2 - (COD: 0.25-0.54), and class 3 - (COD: $\geq 0.55)$. For results from confirmation format ELISA status of the herds was assessed based on published thresholds (23) for percentage of positivity values (PP) as follows: class 0 - (PP: 0-2), class 1 - (PP: 3-13), class 2 - (PP: 14-29), and class 3 - (PP: $\geq 30$ ). Herds in class 0 were regarded as negative, in class 1 had a very low or low level of antibodies in the BTM and were unlikely to harbour PI animals, unless these have been recently introduced. Herds in classes 2 or 3 had a moderate or high level of antibodies, respectively. PI animals were usually found within herds belonging to class 3. Dynamics of antibody decay in BTM samples in herds harbouring PI animals was evaluated in 11 herds where such animals were identified.
Thirty five samples with high COD values in ELISA were tested by reverse transcriptase-polymerase chain reaction (RT-PCR). Milk somatic cells from the bottom of the tubes (cell pellets) were used for extraction of total RNA using TRI Reagent (SIGMAALDRICH, USA), according to the manufacturer's instructions and eluted in a final volume of $10 \mu \mathrm{L}$ or 20 $\mu \mathrm{L}$ of water for BTM and serum samples, respectively. RT-PCR was carried out with the use of a commercial kit (Titan One Tube RT-PCR System, Roche, Germany), following the manufacturer's protocol. The complementary DNA (cDNA) was amplified using forward $324 \mathrm{~F}$ and reverse $326 \mathrm{R}$ primers, specific for 5 'UTR region, sequences of which were published by Vilcek et al. (24). The final volume of RT-PCR reaction mixture was $25 \mu \mathrm{L}$ and it contained: $23 \mu \mathrm{L}$ of reaction mix and $2 \mu \mathrm{L}$ of RNA template. RT-PCR products were visualised by electrophoresis in $1.5 \%$ agarose gel in TAE buffer at $90 \mathrm{~V}$. Confirmation of PI status was based on two positive results in RT-PCR test of serum samples collected from individual animals at least three weeks apart.

The statistical analysis was carried out using Stata v.11.2 (StataCorp, Lakeway Drive, USA) and Microsoft Excel 2007 software. The Kruskal-Wallis rank test and Pearson's correlation test were used for data analysis.

\section{Results}

In the study $70.7 \%$ of herds had BVDV antibodies (classes 1, 2, 3). High levels of antibodies (COD values above 0.55 ) were found in $52.8 \%$ of positive herds (37 herds out of 70 in classes 1, 2, 3), which were classified as class 3 (Fig.1).

Negative herds (lack of BTM antibodies) comprised $29.3 \%$ (29 herds). Five BTM samples representing two herds with high COD values (class 3) were also positive in RT-PCR test giving specific products of expected $288 \mathrm{bp}$ size visible on the agarose gel (Fig. 2) 


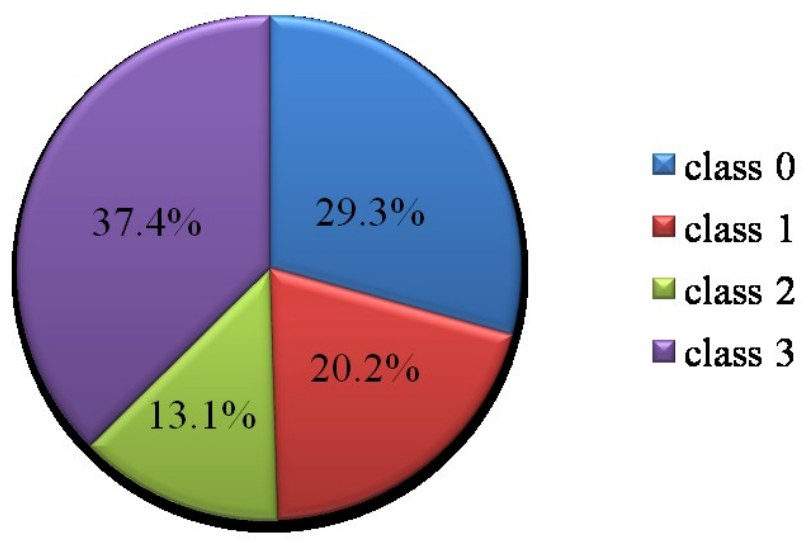

Fig. 1. Distribution of BVDV classes based on ELISA in BTM from 99 dairy herds

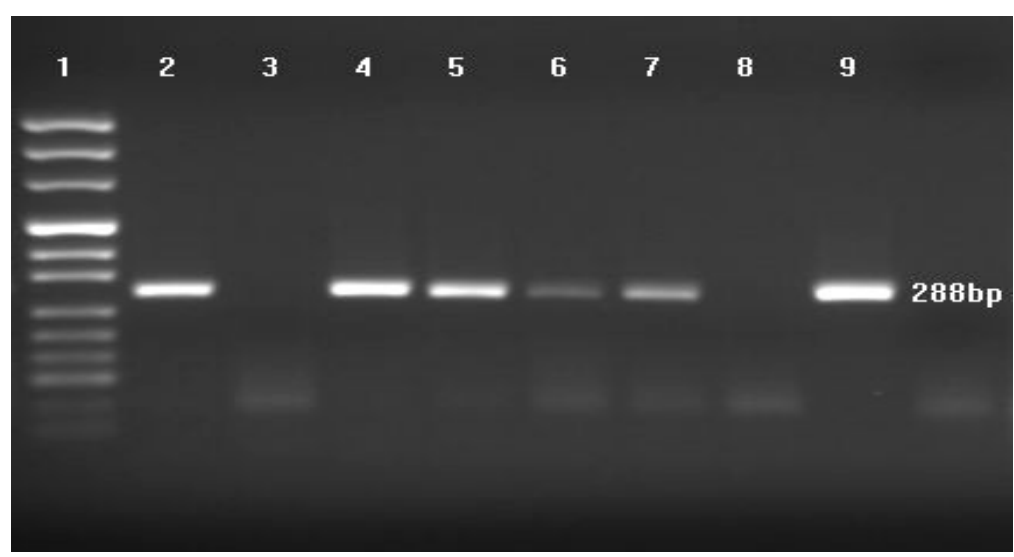

Fig. 2. Agarose gel electrophoresis of amplification products of BVDV RNA. Line 1: pUC Mix Marker 8, Fermentas, lines 2-7: BTM samples, line 8: negative control (commercial foetal bovine serum), line 9: BVDV positive control (serum of PI animal)

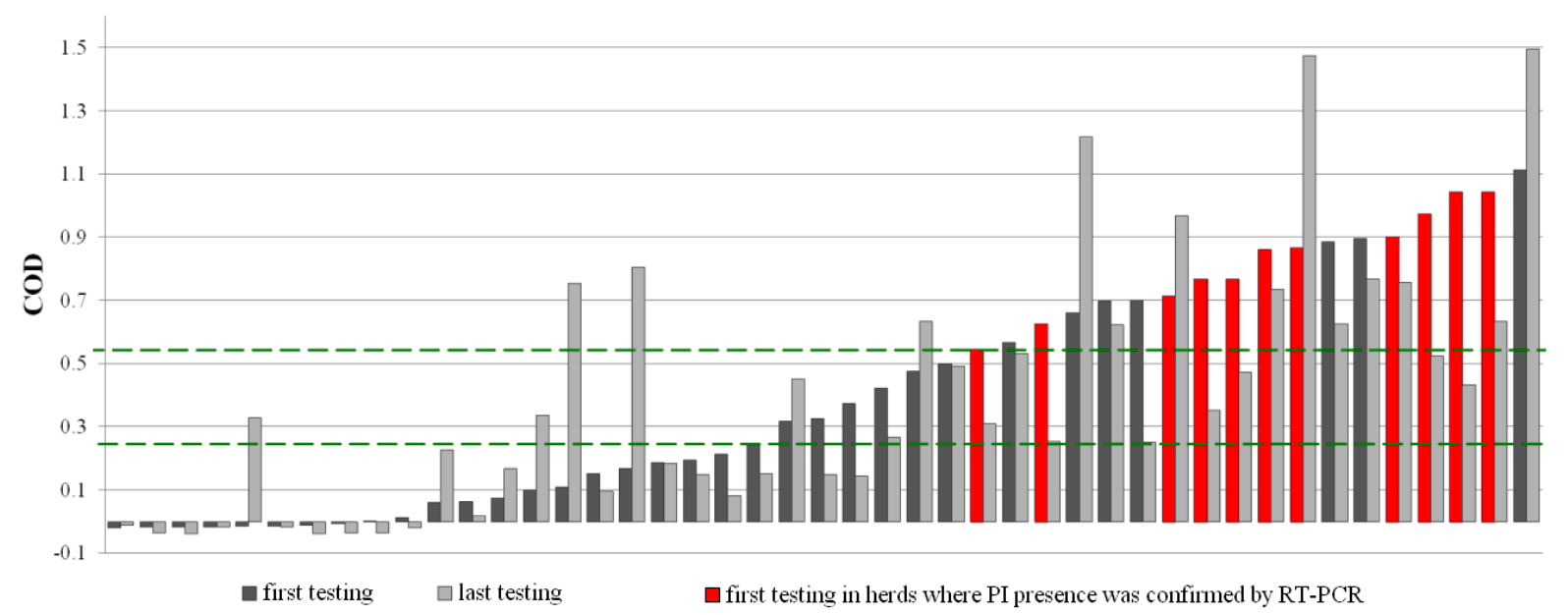

Fig. 3. Distribution of BTM COD values in 45 herds sampled at least twice ordered by the increasing COD value of the first test. The herds where PI animals were confirmed in the sera by RT-PCR are marked in red 
The presence of PI animals was confirmed in 11 herds based on RT-PCR positive test results of serum samples (Fig. 3), which included two herds with positive RT-PCR in BTM samples.

When 45 herds (with and without PIs), which were sampled at least twice, were analysed the BTM COD results of both ELISAs differed significantly when compared using Kruskal-Wallis (11) rank test $(p=0.0001)$. The distribution of COD values for the two samplings is presented in Fig. 3. At the first test, $22.2 \%$, $24.4 \%, 13.3 \%$, and $40.0 \%$ were classified in BTM classes $0,1,2$, and 3 , respectively. At the second testing (including the 11 herds where PIs were identified and removed), $24.4 \%, 17.8 \%, 28.9 \%$, and $28.9 \%$ were considered as class $0,1,2,3$, respectively. BTM class of
$62.2 \%$ herds remained the same in both tests, status of $26.7 \%$ of herds decreased and in $11.1 \%$ of herds it increased (in three herds by two classes and in two herds by one class).

The antibody levels in BTM samples from 11 farms, where PI animals were identified, showed variability of COD values within 18-21 month period after their removal (Fig. 3). Six of these herds (54.5\%) moved from class 3 to class 2, while in two others higher values were obtained on the retest but within the same class 3 . The time of antibody decrease from the removal of PI calves was different for each herd. In one of the herds, the shift from class 3 to class 2 took 30 months, while in another one, the time for the switch between these two classes was 5 months.

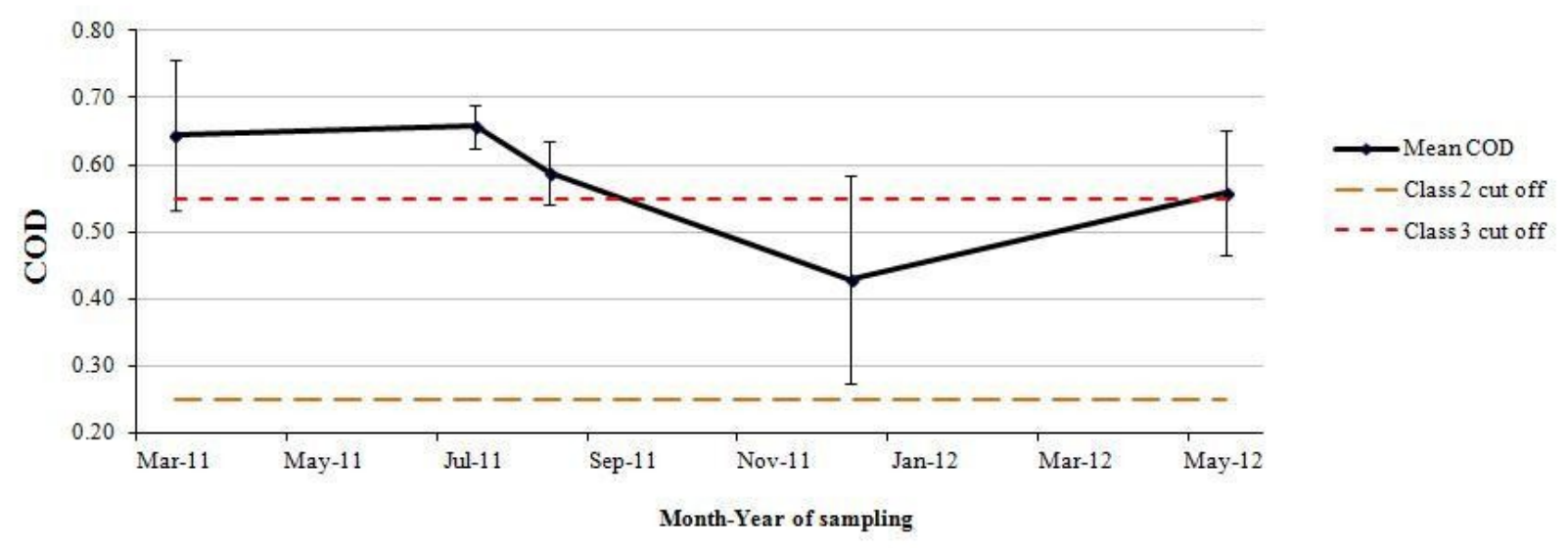

Fig. 4. Mean BTM COD values for three herds from which PI animals were removed. They were sampled on five subsequent occasions. The whiskers indicate standard deviation (SD) values

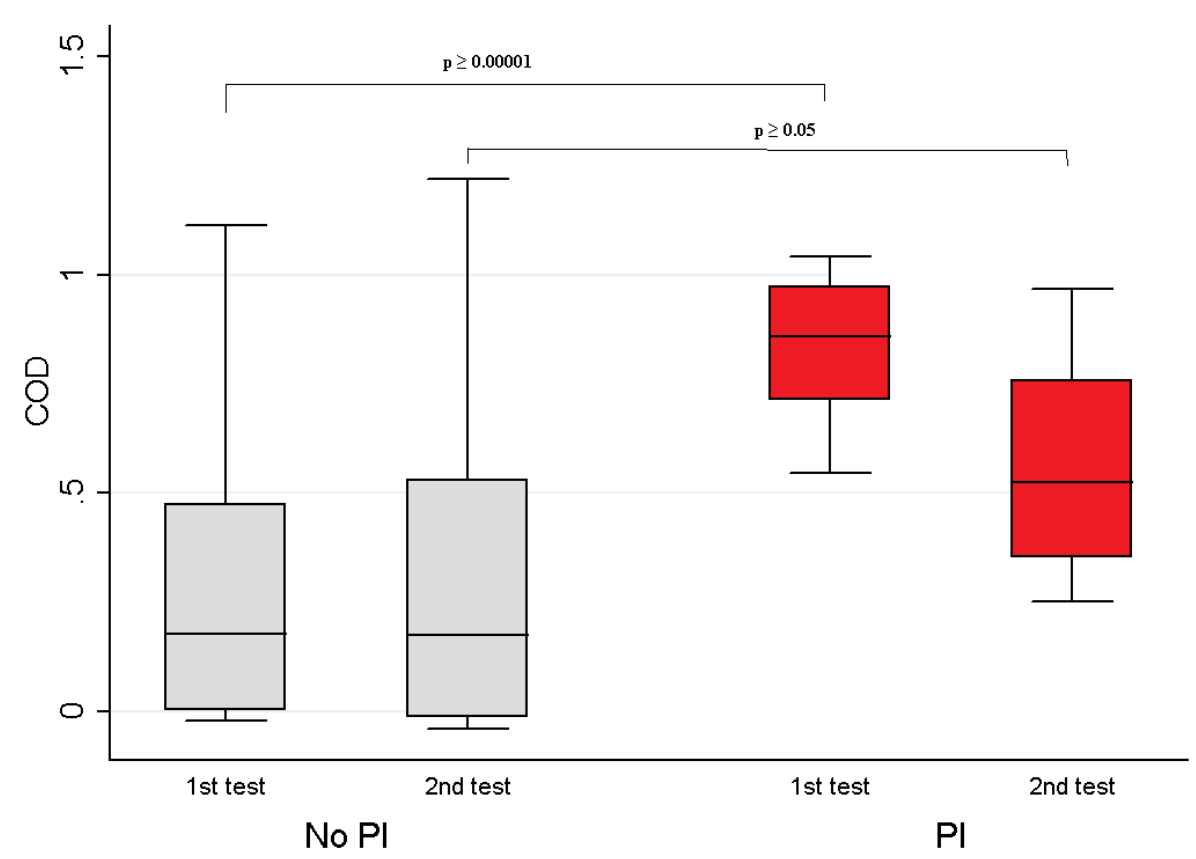

Fig. 5. Comparison of BTM COD values in the herds without/with PI animals in the first and the second testing. Box plots show medians (horizontal bar inside the box), $25^{\text {th }}$ and $75^{\text {th }}$ percentile values (the horizontal limits of the box) and $10^{\text {th }}$ and $90^{\text {th }}$ percentile presented by the whiskers. Brackets mark statistically significant differences between the groups 
The fluctuation of antibody levels in PI herds after the removal of virus shedders was rather stable as shown in Fig. 4. The slope of the regression line drawn for the values of three herds sampled five times in the period of 14 months was only 0.0003 with $\mathrm{R}^{2}$ of 0.37 .

In order to estimate whether the presence of PI animals influences the COD values of herd BTM at the first and second testing, Pearson's correlation was calculated and the differences were presented in the box plots (Fig. 5)

Highly significant difference was observed between BTM COD values at the first testing of the herds with none and with one or more PI animals present $(p \geq 0.00001)$. Smaller difference $(p \geq 0.05)$ between COD values of no PI and PI herds was also observed at the second testing. The overall difference between all herds with PIs present (with mean COD value of 0.83 ; 95\% CI $0.72-0.94$ ) and no PI animals in the herd (with mean COD value of $0.34 ; 95 \%$ CI 0.26 $0.422)$ was highly significant $(\mathrm{p} \geq 0.0005)$. The COD values for the BTM of herds where no PIs were present showed higher variability, classifying the herds in all 4 BTM classes (class 0 to class 3) (Fig. 6A). In comparison, COD values of herds with PI animals located these herds in class 3 on the first testing, and in class 3 and class 2 after the removal of PI animal (Fig. 6B).

The results of screening ELISA and confirmatory ELISA for 28 selected herds at the first testing were compared. The correlation of COD and PP values was significant with $\mathrm{R}^{2}$ of $0.91 \quad(\mathrm{p} \geq 0.0001)$ (Fig. 7). However, the agreement between BTM categorisation based on the two ELISAs was only $57.14 \%$ and kappa value was $0.31(\mathrm{p}=0.0025)(12)$.
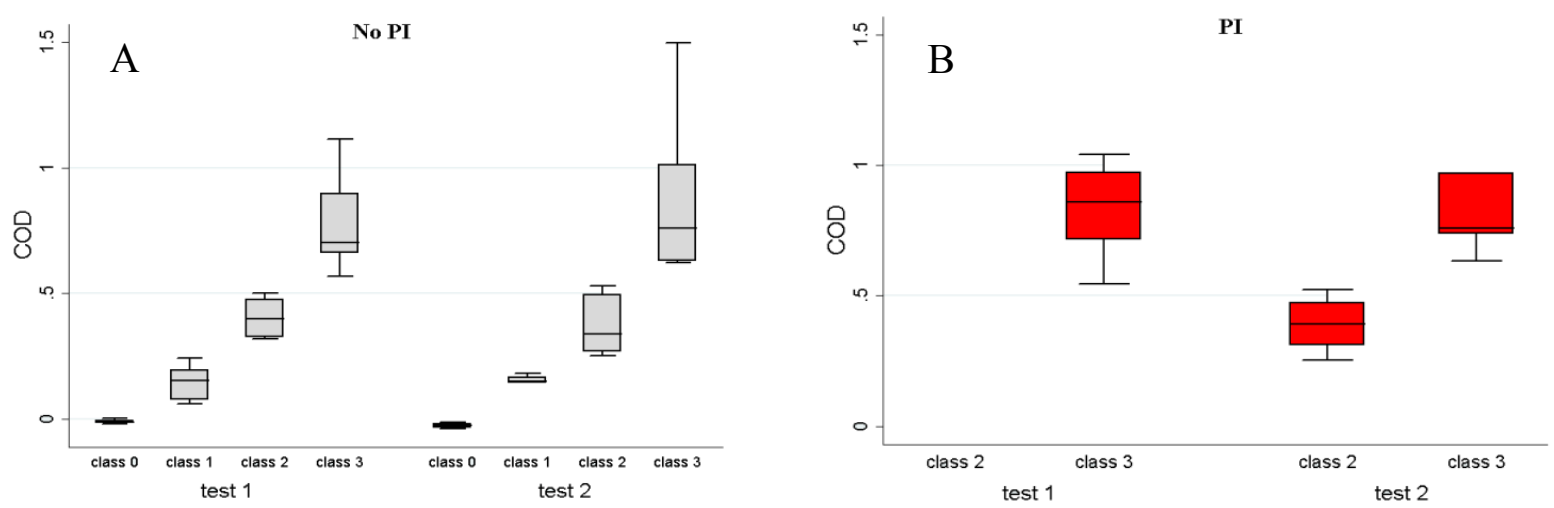

Figs 6. Comparison of BTM COD values in the first (test 1) and the last test (test 2) grouped by BTM class in herds where PIs were detected $(n=11)(B)$ and where PIs were not detected $(n=88)(A)$

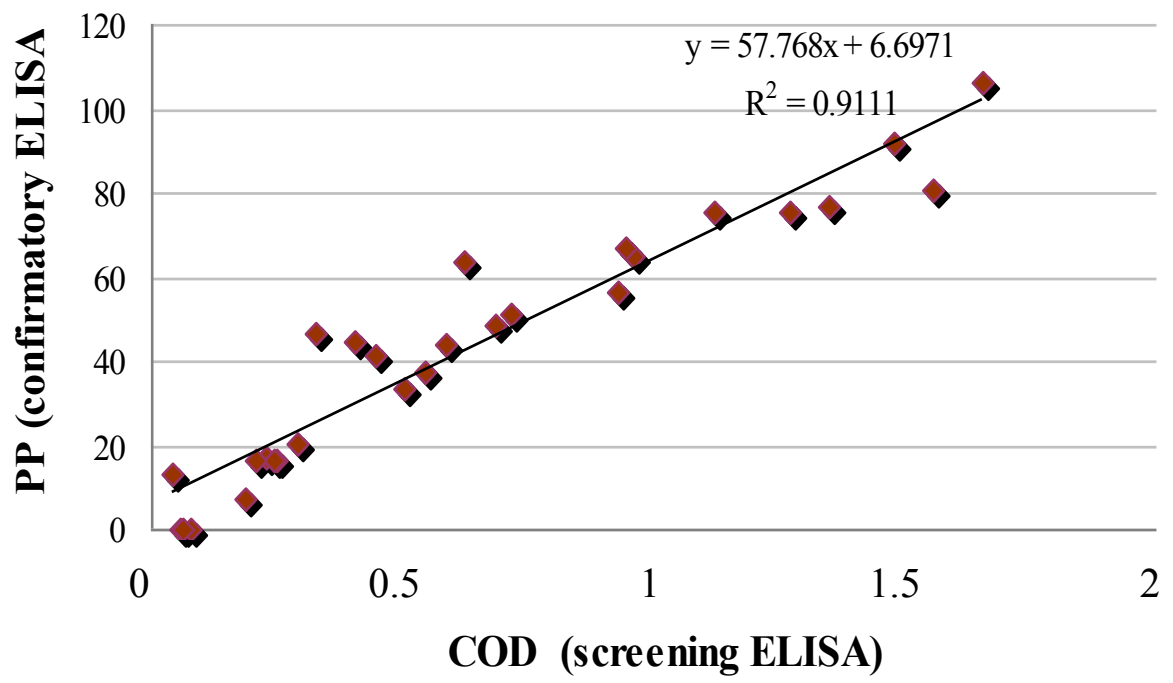

Fig. 7. Correlation of COD values from screening ELISA and PP values from confirmatory ELISA for 28 selected herds 


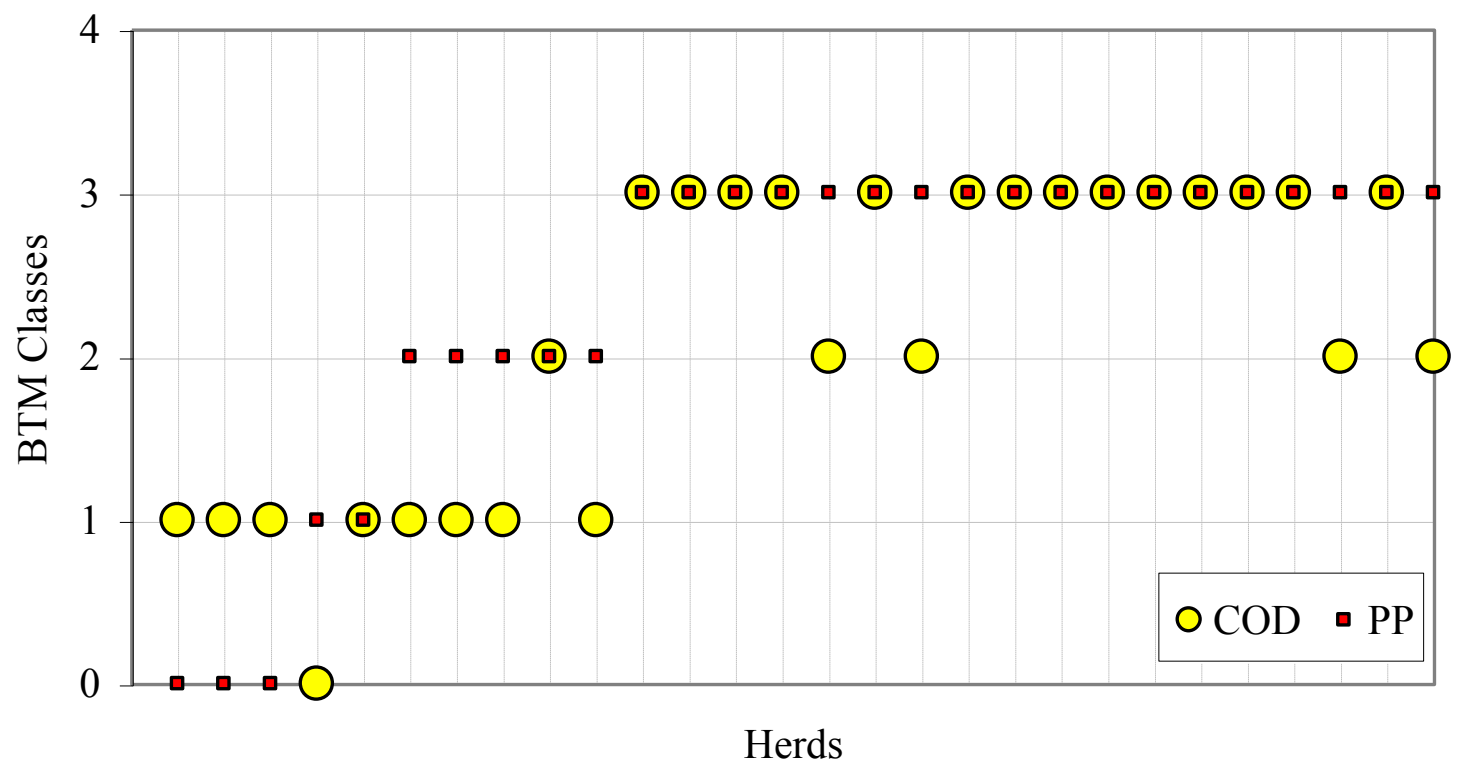

Fig. 8. BTM classification according to COD values of screening ELISA and PP values of confirmatory ELISA of 28 selected herds

Sixteen out of 28 herds were classified in the same class by both tests (Fig. 8). From the remaining 12 herds, nine and three were classified in higher class by confirmatory and screening ELISA, respectively. Those herds, where one-class differences were observed, were equally distributed between classes 0 and 1, 1 and 2, and 2 and 3.

\section{Discussion}

The prevalence of BVDV infection in dairy herds based on BTM ELISA and RT-PCR, used as the cheap and easy alternatives for blood sampling, was evaluated. BTM samples can be collected by a farmer and the analysis of a single sample can provide a reliable picture of the whole herd. Moreover, such an approach can be used to monitor health status of the herd with respect to a new introduction of BVDV into a free herd by a biannual testing of a single BTM sample (4). In general, it can be concluded that dairy herds in Poland have high levels of BVDV antibodies in BTM. The increase in antibody concentration in the second test and positive results in RT-PCR might be associated with the presence of PIs or acutely infected individuals in these herds. Another important issue is how well the biosecurity measures and quarantine are implemented to prevent the introduction of BVDV from the outside. The decay rate of specific antibodies in the herd, even after the removal of PI animals is slow, therefore the eradication programme requires farmers' patience, their education and training on biosecurity measures, and safety of bio-products such as vaccines and hormones, which may be contaminated with BVDV (14).

Over $50 \%$ of the positive herds identified in the study were classified in class 3 , which also indirectly indicates that BVDV is present in these herds or that positive animals were recently removed. Similar studies were undertaken in England, Wales, and Scotland (9, 18). In a study from England and Wales performed in 1998, the prevalence of BVDV antibody-positive herds was estimated at $95 \%$ and approximately $65 \%$ of the herds had a high level of BTM antibodies. However, these results could be biased by the presence of vaccinebased antibodies as the use of vaccines in the UK was allowed since September 1996. However, similar high levels of antibodies were found in a recent study performed in Scotland, where only non-vaccinated herds were involved (9). In that study, $65 \%$ of herds were in class 2 and class 3 according to Swedish scheme. Overall, a $73 \%$ prevalence of herds with high mean levels of antibodies was calculated using statistical model. These results are very similar to our findings, indicating a widespread distribution of BVDV in dairy cattle.

Identification of herds with PI animals is crucial for successful BVDV eradication at a herd level (14). Therefore, the levels of antibodies in BTM of BVDV negative (no PI) and BVDV positive (PI) herds were compared. All herds with PIs were classified in class 3 in the first testing. Despite the removal of PIs from these herds, the dynamics of antibody decay showed rather stable trend with only one class drop in 6 out of 11 PI herds. When one year trend of antibody decay was analysed in three PI herds as mean COD value, again stable values were observed with single class 3 to class 2 change noted 9 months after PI removal, and again the rise to class 3,5 months later. Significant differences in COD values were observed between no PI and PI herds in the first testing with smaller difference observed in the second testing, which can be explained by the fact that the removal of PI animals had an impact on the level of antibodies found in BTM. Therefore, COD value of BTM was considered 
as good predictor for the presence of a PI animal in the herd. The influence of the BVDV eradication (meant as the removal of PI individuals from the herd) in the $2^{\text {nd }}$ test readouts was observed in six herds with PIs compared to 11 such herds. But again the drop was observed only between class 3 and class 2 (both indicating possible presence or recent removal of PI animals).

When comparing two ELISAs in different formats (screening and confirmatory), a high correlation between test readouts and much lower agreement in herd classification was observed. The latter was not so obvious when class 0 and class 1 were treated together as indicating free herds, while class 2 with class 3 together as BVDV positive herds. Following this approach, only four out of 28 herds where screening test classified the herds in class 1 and confirmatory test located the same herds in class 2 were identified. Since BTM testing for BVDV antibodies is an indirect tool to provisionally classify herds as BVDV-free and BVDVinfected, such a simplified approach should not have too much impact on the success of the eradication programme. Therefore, screening test seems to be suitable for initial herd categorisation.

Standard RT-PCR based on 5'UTR primers proved to be a very sensitive test enabling the detection of single PI animals from herds consisting of 550 and 556 milking animals each. Radwan et al. (19) suggested that one PI cow can be detected by RT-PCR in a BTM sample of 5,000 lactating cows based on the studies of serial dilutions of a milk sample from a PI cow. They also noted that levels of BVD virus in milk were higher than those in serum, probably due to the higher levels of cellular elements in milk when compared with serum. Studies of Drew et al. (5) and Kozasa et al. (10) showed that it was possible to identify single PI animals amongst 162 and over 150 milkers, respectively. In our study these values were almost 4-times higher probably due to the use of a different set of primers targeting the same 5'UTR region of viral genome and also due to a lower final volume of water in which the extracted total RNA was resuspended $(10 \mu \mathrm{L}$ opposite to $25 \mu \mathrm{L}$ by Kozasa et al. (10). Several studies indicated that it is possible to distinguish BVDV infected and vaccinated animals using appropriate ELISA (15). However, such analysis was not undertaken since only one sample from a herd vaccinated against BVDV infection was available.

BTM antibody ELISA and RT-PCR are very reliable methods for testing large numbers of animals with relatively little effort. Both methods are also simple and inexpensive alternatives to blood testing, still providing accurate and reliable results (5). While COD value of screening ELISA was considered a good indicator of the presence of a PI animal in a herd, RTPCR test allowed detecting only five out of 11 herds where PI animals were confirmed by individual serum sample testing. It is probably connected with the fact that most PI animals die between 6 and 24 months of age before reaching the first lactation (1). Therefore, viral RNA detected in the BTM samples relates probably to transient BVDV infections in a herd, which in most cases are subclinical.
Systematic testing of dairy herds with the method described in the study, provides an early warning system and enables to detect newly introduced infected animals, thus it helps to eradicate the disease and to control BVDV spreading.

Acknowledgements: Technical assistance of Malgorzata Glowacka and Agnieszka Nowakowska is highly appreciated.

\section{References}

1. Brownlie J., Clarke M.C., Howard C.J.: Experimental production of fatal mucosal disease in cattle. Vet Rec 1984, 114, 535-536

2. Carlsson U.: Border disease in sheep caused by transmission of virus from cattle persistently infected with bovine virus diarrhoea virus. Vet Rec 1991, 128, 145-147.

3. Depner K., Hubschle O.J.B., Liess B.: BVD-virus infection in goats - experimental studies on transplacental transmissibility of the virus and its effect on reproduction. Arch Virol Suppl 1991, 3, 253-256.

4. Dieguez F.J., Yus E., Sanjuan M.L., Vilar M.J., Arnaiz I.: Monitoring bovine viral diarrhea virus (BVDV) infection status in dairy herds. Pesq Vet Bras 2008, 28, 588-592.

5. Drew T.W., Yapp F., Paton D.J.: The detection of bovine viral diarrhoea virus in bulk milk samples by the use of a single-tube RT-PCR. Vet Microbiol 1999, 64, 145-154.

6. Fauquet C.M., Mayo M.A., Maniloff J., Desselberger U., Ball L.A.: Virus Taxonomy. Eight Report of the International Committe on Taxonomy of Viruses. Elsevier Academic Press, Hongkong, 2005, p. 992.

7. Gunn G.J., Saatkamp H.W., Humphry R.W., Statt A.W.: Assessing economic and social pressure for the control of bovine viral diarrhoea virus. Prev Vet Med 2005, 72, 149 162.

8. Houe H.: Economic impact of BVDV infection in dairies. Biologicals 2003, 31, 137-143.

9. Humphry R.W., Brulisauer F., McKendrick I.J., Nettleton P.F., Gunn G.J.: Prevalence of antibodies to bovine viral diarrhoea virus in bulk tank milk and associated risk factors in Scottish dairy herds. Vet Rec 2012, 171, p. 445.

10. Kozasa T., Tajima M., Yasutomi I., Sano K., Ohashi K., Onuma M.: Relationship of bovine viral diarrhea virus persistent infection to incidence of diseases on dairy farms based on bulk tank milk test by RT-PCR. Vet Microbiol 2005, 106, 41-47.

11. Kruskal W.H., Wallis W.A.: Use of ranks in one-criterion variance analysis. J Am Stat Assoc 1952, 47, 583-621.

12. Landis J.R., Koch G.G.: The measurement of observer agreement for categorical data. Biometrics 1977, 33, 159174.

13. Lindberg A., Groenendaal H., Alenius S., Emanuelson U.: Validation of a test for dams carrying foetuses persistently infected with bovine viral-diarrhoea virus based on determination of antibody levels in late pregnancy. Prev Vet Med 2001, 51, 199-214.

14. Lindberg A., Houe H.: Characteristics in the epidemiology of bovine viral diarrhea virus (BVDV) of relevance to control. Prev Vet Med 2005, 72, 55-73.

15. Makoschey B., Sonnemans D., Munoz Bielsa J., Frenken P., Mars M., Santos L., Alvarez M.: Evaluation of the induction of NS3 specific BVDV antibodies using a commercial inactivated BVDV vaccine in immunization and challenge trials. Vaccine 2007, 25, 6140-6145. 
16. Moennig V., Liess B.: Pathogenesis of intrauterine infections with bovine viral diarrhea virus. Vet Clin North Am Food Anim Pract 1995, 11, 477-487.

17. Niskanen R.: Relationship between the levels of antibodies to bovine viral diarrhoea virus in bulk tank milk and the prevalence of cows exposed to the virus. Vet Rec 1993, 133, 341-344.

18. Paton D.J., Christiansen K.H., Alenius S., Cranwell M.P., Pritchard G.C., Drew T.W.: Prevalence of antibodies to bovine virus diarrhoea virus and other viruses in bulk tank milk in England and Wales. Vet Rec 1998, 142, 385391.

19. Radwan G.S., Brock K.V., Hogan J.S., Smith K.L.: Development of a PCR amplification assay as a screening test using bulk milk samples for identifying dairy herds infected with bovine viral diarrhea virus. Vet Microbiol 1995, 44, 77-92.

20. Rikula U., Nuotio L., Aaltonen T., Ruoho O.: Bovine viral diarrhoea virus control in Finland 1998-2004. Prev Vet Med 2005, 72, 139-142.

21. Rypuła K., Kaba J., Płoneczka-Janeczko K., WojewodaKotwica B., Kumala A., Mazurkiewicz M.:
Epidemiological aspects of BVDV infections in dairy cattle herds in Poland. Med Weter 2010, 66, 684-687.

22. Straver P.J., Journee D.L., Binkhorst G.J.: Neurological disorders, virus persistence and hypomyelination in calves due to intra-uterine infections with bovine virus diarrhoea virus. II Virology and epizootiology Vet Q 1983, 5, 156164.

23. SVANOVA: The "Swedish" herd classification system described by Niskanen R., Alenius S., Larsson B., Jacobsson S.O. transferred to use of the commercially available SVANOVIR BVDV-Ab ELISA (art \# 10-220002). SVANOVA 2005, Manual number: 19-2200-0094/04.

24. Vilcek S., Herring A.J., Herring J.A., Nettleton P.F., Lowings J.P., Paton D.J.: Pestivirus isolated from pigs, cattle, and sheep can be allocated into at least three genogroups using polymerase chain reaction and restriction endonuclease analysis. Arch Virol 1994, 136, 309-323.

25. Wittum T.E., Grotelueschen D.M., Brock K.V., Kvasnicka W.G., Floyd J.G., Kelling C.L., Odde K.G.: Persistent bovine viral diarrhoea virus infection in US beef herds. Prev Vet Med 2001, 13, 83-94. 